\title{
Perancangan Souvenir Kaos Probolinggo sebagai Pengenalan Identitas Daerah untuk Wisatawan
}

\author{
Tiara Rizky Marsha Laduni dan Sayatman \\ Departemen Desain Komunikasi Visual, Fakultas Arsitektur, Desain dan Perencanaan, \\ Institut Teknologi Sepuluh Nopember (ITS) \\ e-mail: sayatasik@gmail.com
}

\begin{abstract}
Abstrak - Probolinggo merupakan daerah destinasi wisata di Jawa Timur yang memiliki keunggulan pada keanekaragaman wisata alam, kesenian, dan kebudayaan. Hal tersebut menjadi daya tarik karena mencerminkan nilai jual sekaligus keunggulan daerah Probolinggo. Oleh karena itu Probolinggo harus memberi kesan baik pada wisatawan yang dapat ditawarkan melalui souvenir. Dilakukan riset dengan metode depth interview pada Dinas Pariwisata dan Kebudayaan Probolinggo dan pemilik brand clothing lokal, observasi, kajian literatur bersumber pada buku pedoman kepariwisataan. Perancangan ini diharapkan memberikan solusi terhadap kebutuhan souvenir Probolinggo yang layak serta mempresentasikan potensi daerah Probolinggo yang dibutuhkan oleh wisatawan.
\end{abstract}

Kata Kunci-Souvenir, Kaos, Identitas Daerah, Probolinggo.

\section{PENDAHULUAN}

$\mathrm{D}$ AERAH Probolinggo memiliki budaya, daerah pegunungan hingga laut, dan industri yang menjadi potensi yang dapat diunggulkan. Dari segi budaya Probolinggo mengembangkan kesenian dan budaya selain itu Probolingo memiliki keindahan alam yang menjadi andalan wisata. Oleh karena itu Probolinggo sejak tahun 2009 hingga saat ini menjadi salah satu destinasi pilihan Pesiar berkapasitas 2.600 penumpang yang berlayar ke Indonesia [1]. Oleh karena itu Probolinggo sebagai daerah wisata dituntut untuk memberikan kesan baik terhadap wisatawan yang berkunjung, salah satunya dengan souvenir.

\section{A. Latar Belakang}

Ketersediaan souvenir di Probolinggo sebagai daerah destinasi wisata masih sangat kurang, hal ini didukung dengan kuisioner terhadap para penduduk dan wisatawan Probolinggo. Dari 67.3\% dari 150 responden belum pernah membeli souvenir Probolinggo karena tidak tahu apa yang dapat dibeli, $82.2 \%$ dari 151 responden yang pernah membeli merasa belum puas dengan souvenir yang pernah dibuat di Probolinggo.

Dengan mengelola kegiatan promosi dan membuat perbedaan identitas dengan daerah lainnya, oleh karena itu souvenir dapat dijadikan sebagai media untuk menunjukkan ciri khas dan keunikan suatu daerah. Oleh karena itu, kuantitas dan kualitas dari souvenir di Probolinggo perlu ditingkatkan dengan menerapkan prinsip desain dan memperhatikan estetika dalam mengolah visual ragam potensi dimiliki Probolinggo yang diaplikasikan pada media souvenir yang menunjukkan potensi dan ciri khas yang dimiliki daerah Probolinggo.

\section{B. Identifikasi Masalah}

Terdapat beberapa hal yang mendorong diperlukannya perancangan souvenir untuk daerah Probolinggo yaitu :

1. Daerah Probolinggo sebagai daerah destinasi wisata tidak memiliki souvenir dengan grafis yang menunjukkan potensi yang dimiliki Probolinggo.

2. Beberapa souvenir yang pernah diproduksi seperti kaos dan piring mini tidak layak untuk ditawarkan kepada wisatawan lokal maupun asing.

3. Diperlukan desain souvenir yang menarik, unik, mencerminkan identitas daerah Probolinggo yang dibutuhkan wisatawan.

\section{Batasan Masalah}

Melalui masalah yang ditemukan maka diperlukan batasan yang akan dikerjakan serta dicari solusinya. Batasan tersebut yaitu :

1. Peneliti merencanakan sebuat rancangan souvenir dengan mengangkat objek yang menjadi potensi kepariwisataan Probolinggo.

2. Penelitian ini membahas proses perancangan grafis untuk diaplikasikan pada kaos sebagai souvenir Probolinggo

\section{Rumusan Masalah}

"Bagaimana merancang souvenir kaos daerah Probolinggo yang mempresentasikan identitas Probolinggo yang dibutuhkan wisatawan?"

\section{E. Maksud dan Tujuan}

1. Merancang grafis untuk souvenir berupa kaos yang menunjukkan potensi wisata dan kesenian Probolinggo yang dibutuhkan oleh wisatawan.

2. Mengolah visual Probolinggo melalui konteks style/ gaya gambar ilustrasi sebagai salah satu daerah di yang memiliki potensi wisata serta budaya dalam media souvenir kaos.

\section{TINJAUAN PUSTAKA}

\section{A. Landasan teori}

1. Kajian teori subjek desain

Souvenir merupakan hal yang tidak luput ketika mengunjungi suatu daerah wisata bagi wisatawan. Souvenir adalah sesuatu yang mengkongkritkan kedaan tak 
berwujud menjadi sesuatu yang berbentuk [2]. Keberadaan secara fisik tersebut mengendalikan calon konsumen untuk mengabadikan pengalaman yang biasa maupun tidak biasa di masa lalu. Pembeli memilih souvenir dari segi desain, kualitas yang baik, warna-warna yang atraktif, selain itu souvenir dibeli adalah souvenir yang memiliki ciri khas daerah yang dikunjungi wisatawan [3].

Maka, secara keseluruhan souvenir merupakan produk yang mengkomunikasikan hubungan antara sesorang dengan pengalaman tertentu yang mereka dapat melalui benda kasat mata.

2. Kajian Teori Objek Desain

Probolinggo merupakan salah satu daerah yang mulai berkembang di Provinsi Jawa Timur. Karena dikelilingi pegunungan dan memiliki daerah pesisir, Probolinggo memiliki keragaman potensi wisata alam yang dapat diandalkan. Selain itu, secara sosiologis penduduk Probolinggo didominasi oleh masyarakat Jawa dan percampuran Madura, serta terdapat salah satu suku di pegunungan Bromo yaitu suku Tengger, oleh karena itu Probolinggo memiliki kebudayaan dan kesenian yang dapat diunggulkan diferensiasinya.

Keragaman wisata alam Probolinggo saat ini menjadi potensi wisatawan diantaranya Gunung Bromo, Air Terjun Madakaripura, Sungai Arung Jeram Songa, dan Gili Ketapang. Selain itu, Probolinggo memiliki wisata landmark yaitu cagar bangunan Gereja Merah dan objek ekowisata Beejay Bakau Resort. Serta keragaman seni dan kebudayaan seperti Tari Glipang, Jaran Bodhag, Karapan Kambing, dan Upacara Kasada.

\section{B. Pengertian T-Shirt sebagai Souvenir}

Wisatawan berorientasi pada tempat tujuan wisata membeli souvenir berupa produk garment seperti T-shirt yang bergambar tempat wisata, hal tersebut berfungsi untuk menunjukkan pengalaman perjalanan yang istimewa ketika berwisata yang dapat digunakan dalam keseharian. Kebutuhan yang wisatawan rasakan, membuat mereka ingin mengabadikan pengalaman yang mereka rasakan telah meningkatkan industri penting dari "kenangan" dan "souvenir", ditujukan untuk mewujudkan suatu produk yang dibeli oleh wisatawan untuk kebutuhan mereka sendiri dan juga dapat digunakan sebagai oleh-oleh untuk lingkungan sosial terdekatnya (Schhluter,1993).

\section{METODE PENELITIAN}

\section{A. Metode Pengumpulan Data}

Metode pengumpulan data yang digunakan oleh penulis adalah sebagai berikut:

\section{1) Data Primer}

a. Observasi

Observasi ini dilakukan langsung oleh peneliti pada bulan Juni 2018 hingga September 2018.

b. Dokumentasi Foto

Data berupa gambar didapat oleh penulis dari dengan mengambil beberapa foto destinasi, eksisting dan souvenir.

\section{Depth Interview}

Melakukan wawancara mendalam dengan beberapa pihak yang berkaitan dengan subjek penelitian diantaranya adalah:
Ibu Suci Ningsih, Kabid Promosi Disbudpar Kota Probolinggo. : Memberikan informasi seputar data wisatawan di Probolinggo. Serta membahas souvenir eksisting dan karakteristik suvenir Probolinggo yang diharapkan.

3.

Mas Uji, Owner Clothing Insprd27 :

Membahas hingga proses kreatif desain dalam kaos, masalah penjualan dan promosi dalam memperkenalkan brand. Memberikan saran untuk membangun brand untuk souvenir kaos Probolinggo.

3. Kuisioner disebarkan melalui internet (google forms)

\section{B. Proses Perancangan}

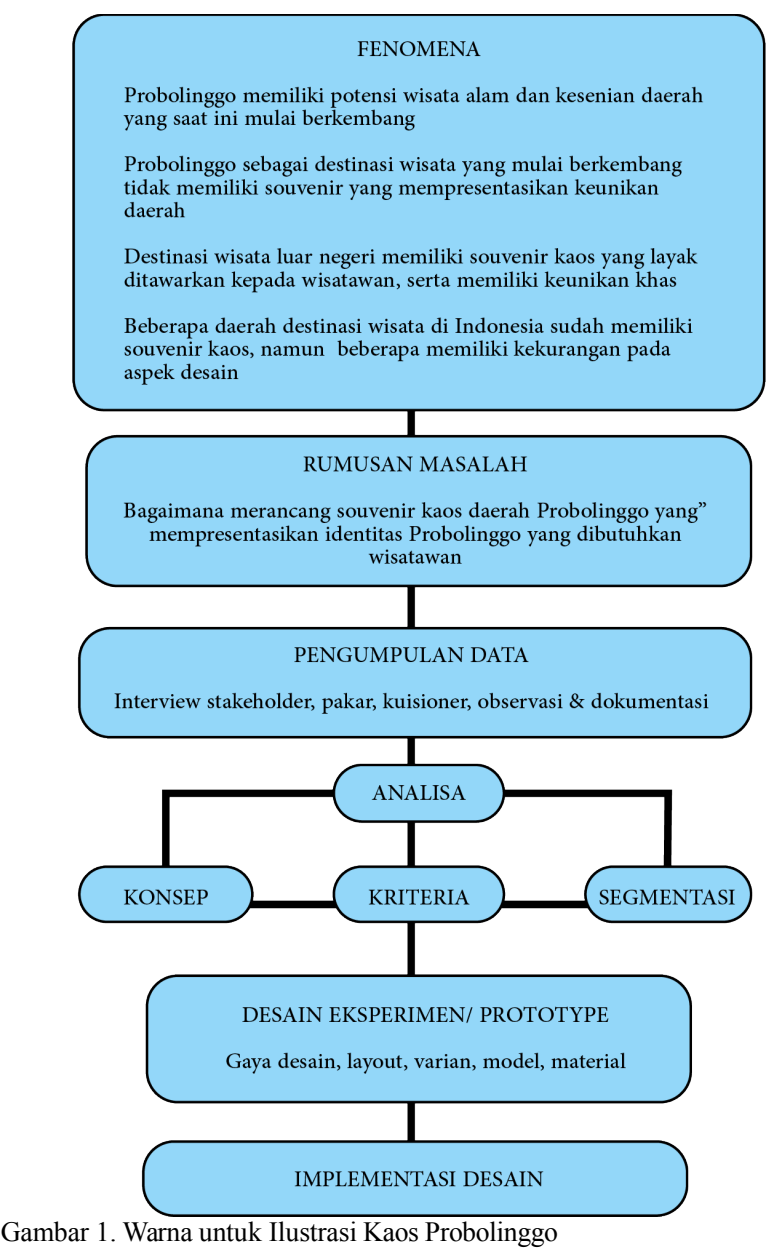

Bersumber pada pengumpulan dan temuan fenomena, penulis merumuskan permasalahan kemudian mencari data yang terkait dengan subjek perancangan. Pencarian data dilakukan untuk mendapatkan hasil dan analisa dalam merumuskan konsep desain, selain itu untuk mendapatkan kriteria desain yang dibutuhkan segmentasi. Melalui tiga hal tersebut, penulis melakukan eksperimen desain untuk menemukan gaya desain yang tepat, varian layout dan model kaos. Setelah gaya desain didapatkan, penulis mengaplikasikan pada kaos, sebagai implementasi desain.

\section{HASIL DAN KESIMPULAN}




\section{A. Analisa dan Hasil Pengumpulan Data}

1. Interview dengan ibu Suci Ningsih selaku Kabid Disbudpar Probolinggo, menyatakan selama 7 tahun terakhir pariwisata di Probolinggo meningkat, terutama dengan adanya pesiar yang singgah di Proboolinggo. Wisatawan mencari souvenir yang mencerinkan Probolinggo, simple dan praktis.

1. Deep Interview dengan Mas Uji selaku pemilik brand Inspird27, brand clothing saat ini mulai marak di kalangan remaja. Seiring bergantinya trend, sebuah clothing brand dapat mengkolaborasikan konsep yang dimiliki dengan trend yang sedang berjalan. Untuk membuat clothing, terutama souvenir, hendaknya menggali potensi yang unik dan khas yang ada di Probolinggo.

2. Hasil Kuisioner terhadap 150 responden, 56,3\% memilih souvenir kaos .

\section{B. Karakteristik Target Audiens}

1. Demografis Segmentasi

a. Usia : usia 18- 25 tahun

b. Jenis kelamin : laki-laki dan perempuan

c. Domisili : domestik dan mancanegara

d. Penghasilan perbulan : $\geq$ Rp. $500.00-$ Rp.3.000.000 perbulan

e. Pendidikan terakhir : $\mathrm{S} 1$

f. Pekerjaan : mahasiswa, pegawai, pengusaha muda

2. Geografis

Masyarakat yang bertempat tinggal di Indonesia atau pernah mengunjungi Probolinggo sebagai destinasi wisata.

3. Psikografis

a. Suka berpergian

b. Menyukai wisata alam dan kegiatan yang ada di dalamnya.

c. Menghargai dan tertarik dengan kebudayaan dan seni daerah lokal.

d. Pengguna brand lokal.

e. Mengikuti perkembangan teknologi.

\section{PROSES DAN IMPLEMENTASI DESAIN}

A. Konsep Desain

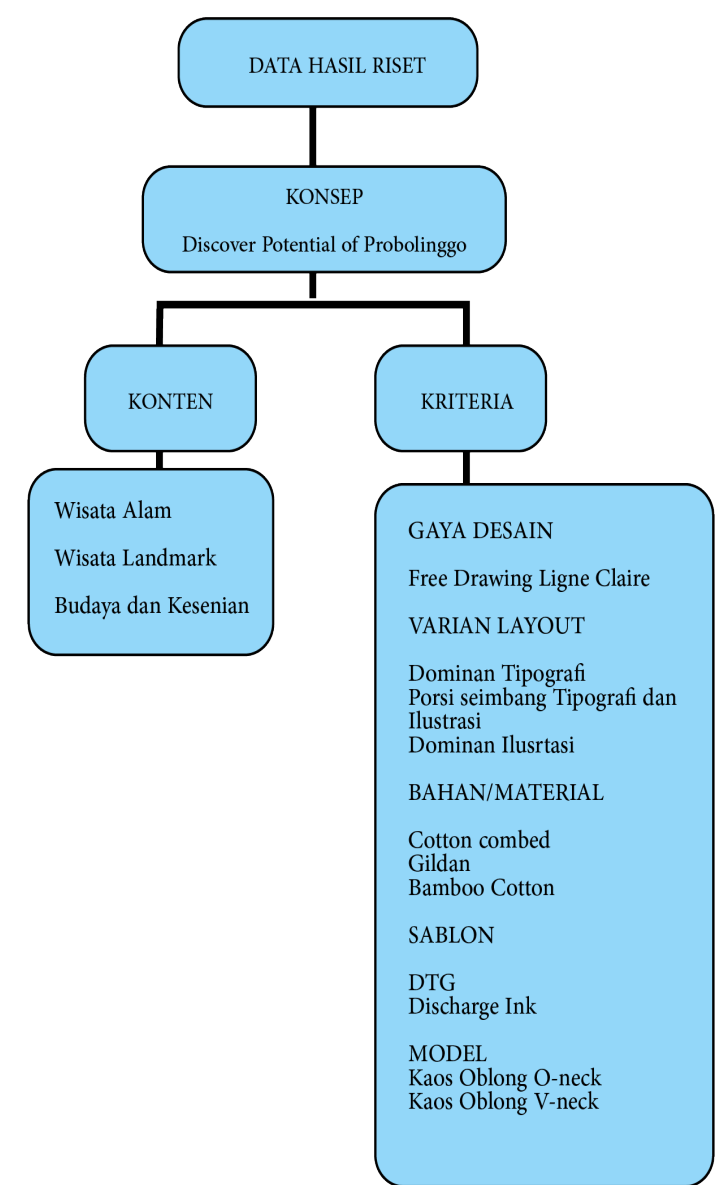

Gambar 1. Bagan konsep desain souvenir kaos Probolinggo.

Bersumber dari hasil dan Analisa, maka ditentukan konsep desain yaitu "Discover Protential of Probolinggo". Makna dari keyword tersebut adalah menjelajahi potensi wisata serta kesenian dan budaya Probolinggo yang khas, unik dan orisinil, kemudian dikemas dalam suatu ilustrasi. Konsep desain tersebut diimplementasikan dengan teknik free drawing yang terpengaruh oleh gaya desain Clear Line atau Ligne Claire.

1.

Merk souvenir : Probolinggo Jeh !

Merk brand souvenir kaos Probolinggo bernama "Probolinggo Jeh !". "Jeh" merupakan sapaan akrab Bahasa pendalungan (percampuran Jawa-Madura) seperti "Bro!". Diharapkan memiliki citra yang menarik dan dapat memperkenalkan Probolinggo dengan akrab pada pemakai atau konsumen.

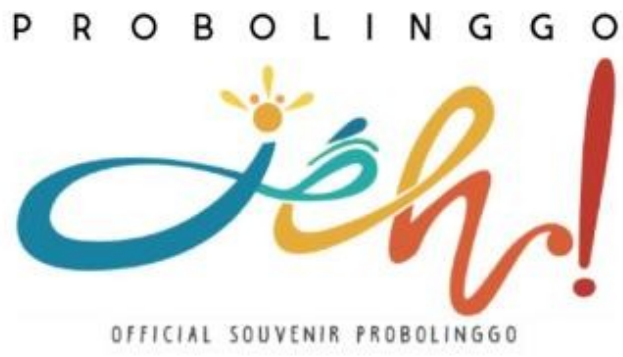

Gambar 3. Logo "Probolinggo Jeh!"

\section{Tipografi}

Tipografi yang digunakan pada perancangan souvenir kaos Probolinggo berjenis script dan san serif karena mudah terbaca dan memberi kesan modern, fun dan fresh, sehingga dapat mewakili karakteristik Probolinggo sebagai kawasan wisata budaya. 


\begin{tabular}{|c|c|c|}
\hline Nama Font & Jenis & Contoh \\
\hline Hand of Sean & Script (Handwritten) & Probolinggo \\
\hline Kalissa & Script & Probodingge \\
\hline Sontoloyo & Script & Probolinggo \\
\hline Ikaros & San serif & Probolinggo \\
\hline
\end{tabular}

2. Warna

Warna yang digunakan adalah warna yang mampu menggambarkan suasana dan Probolinggo tujuannya yaitu mempresentasikan image sebagai daerah dengan potensi wisata alamd dengan keunggulan wisata alam, mengambil tema mengikuti dengan branding Endless Probolinggoo pada saat ini yaitu warna yang fun dan cerah.

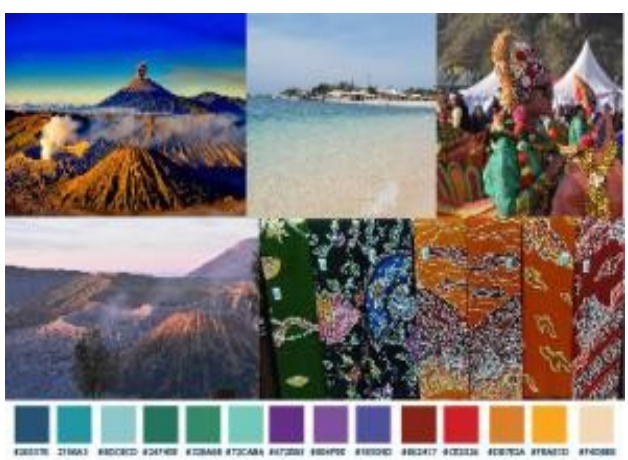

Gambar 4. Bagan Perancangan souvenir kaos Probolinggo.

B. Proses Desain dan Implementasi

1. Proses Sketsa dan Digitalisasi
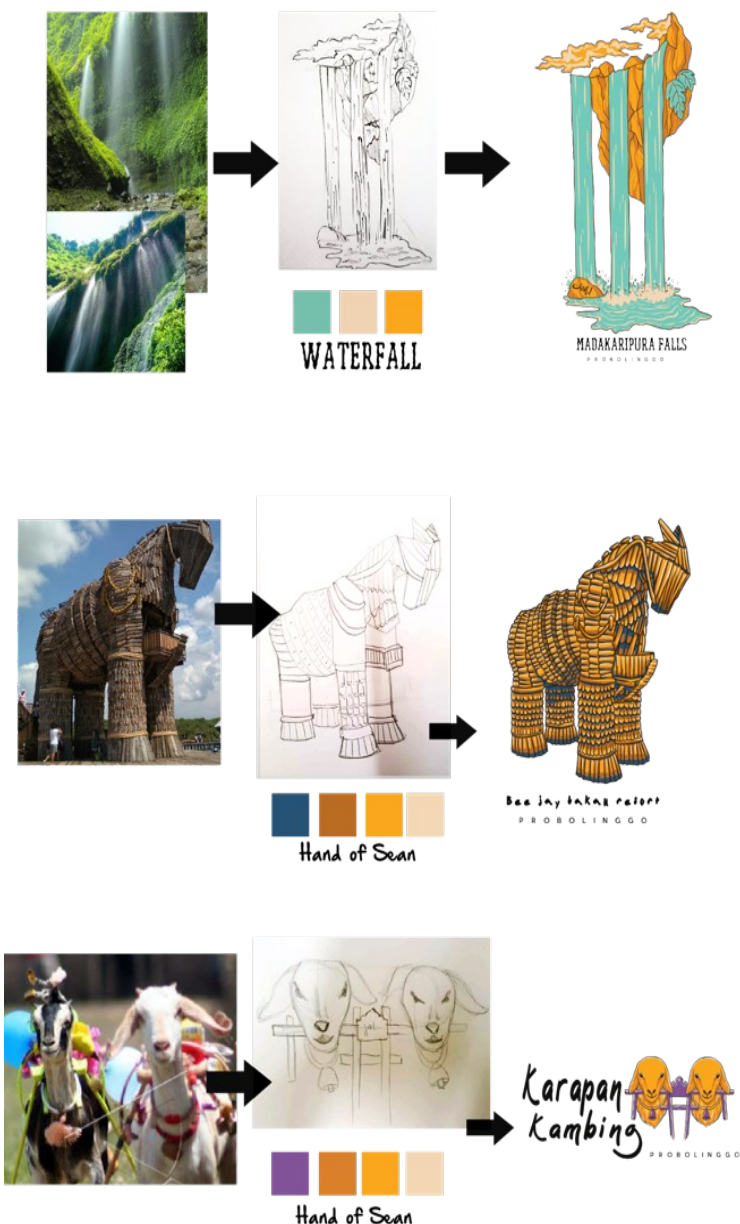

Gambar 2. Proses desain Ilustrasi Kaos

Dalam mendesain ilustrasi untuk kaos Probolinggo, dilakukan proses brainstorming ide. Setelah itu mencari referensi gambar untuk ilustrasi, sketsa manual, kemudian dilakukan proses digitalisasi sketsa yang dikombinasikan dengan tipografi yang sesuai konten.

2. Hasil Desain

Setelah melalui proses sketsan dan digital, maka dihasilkan desain yang dikelompokkan dari konten dan varian layout.

a. Konten Wisata Landmark

Dalam edisi landmark meliputi Gereja Merah dan BJBR.

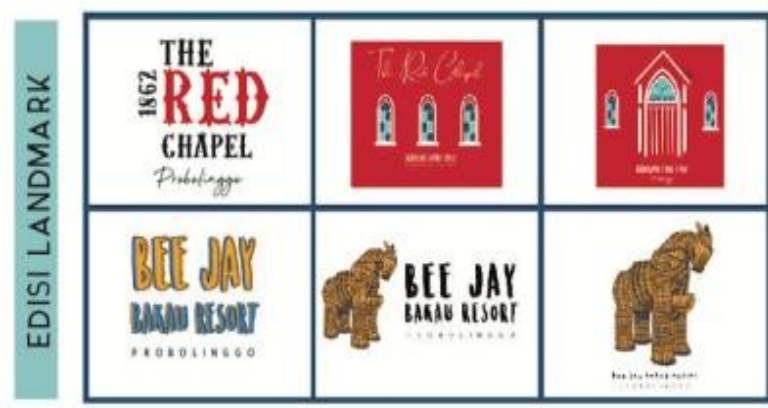

Gambar 3 Edisi Landmark

b. Konten Wisata Alam

Dalam edisi wisata alam meliputi konten Bromo, Madakaripura, Songa, dan Gili Ketapang. 


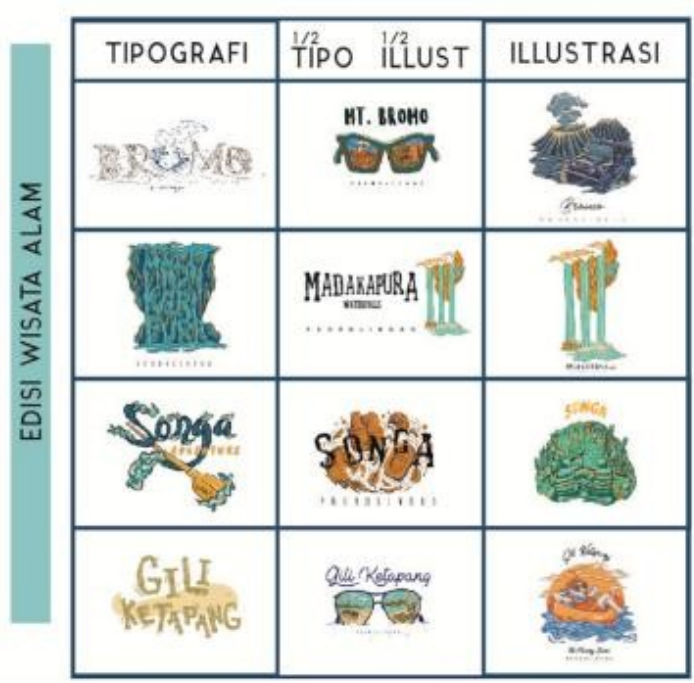

Gambar 4 Edisi Wisata Alam

c. Konten Kesenian Budaya

Dalam edisi kesenian budaya meliputi konten Jaran Bodhag, Tari Glipang, Karapan Kambing dan Kasada.

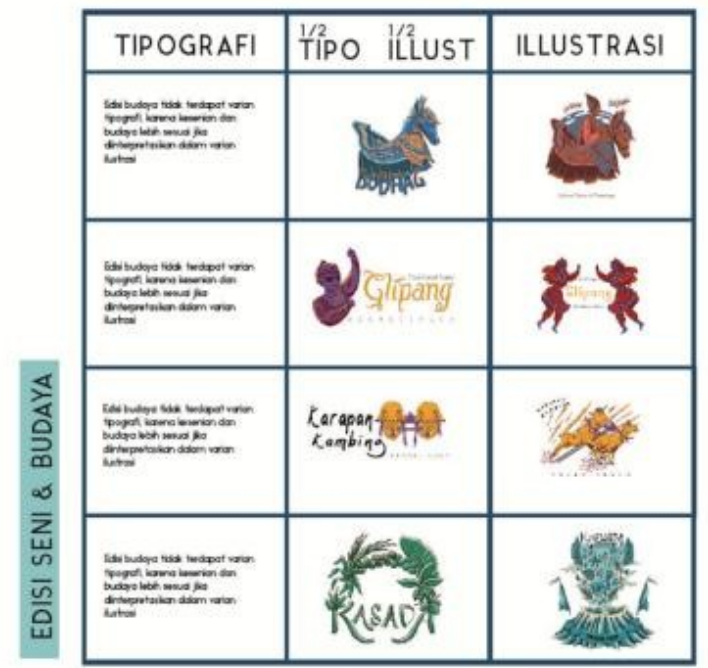

Gambar 5 Edisi Wisata Budaya dan Kesenian

Pada edisi Kesenian Budaya tidak memiliki varian Tipografi, karena konten Kesenian lebih tepat diaplikasikan dalam varian yang ilustratif.

3.Implementasi Desain

Berikut adalah hasil jadi dari kaos souvenir Probolinggo. Kaos bersifat unisex dapat dikenakan pria ataupun wanita tergantung selera pada desain user.

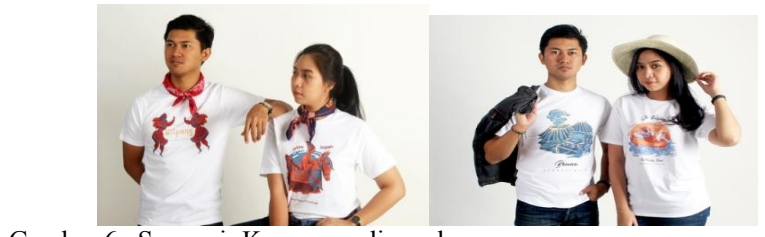

Gambar 6 . Souvenir Kaos yang digunakan user

\section{Implementasi Logo}

Logo diaplikasikan pada packaging, label, serta brandmark yang digunakan sebagai media sekunder untuk mengenalkan souvenir kaos Probolinggo dengan informasi tentang Probolinggo.
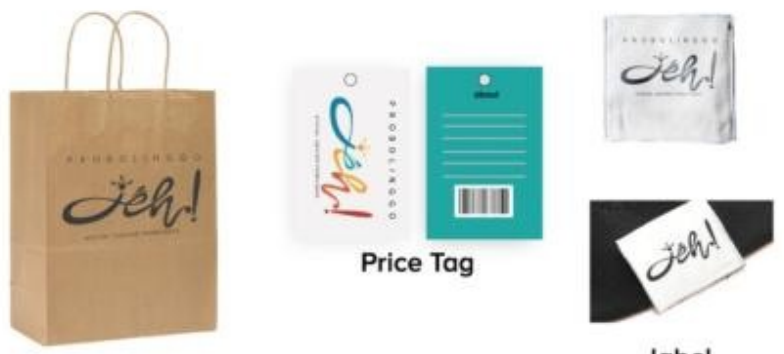

label

Shopping bag

Gambar 7 Pengaplikasian logo pada label dan packaging.

\section{Konsep Bisnis dan Produksi}

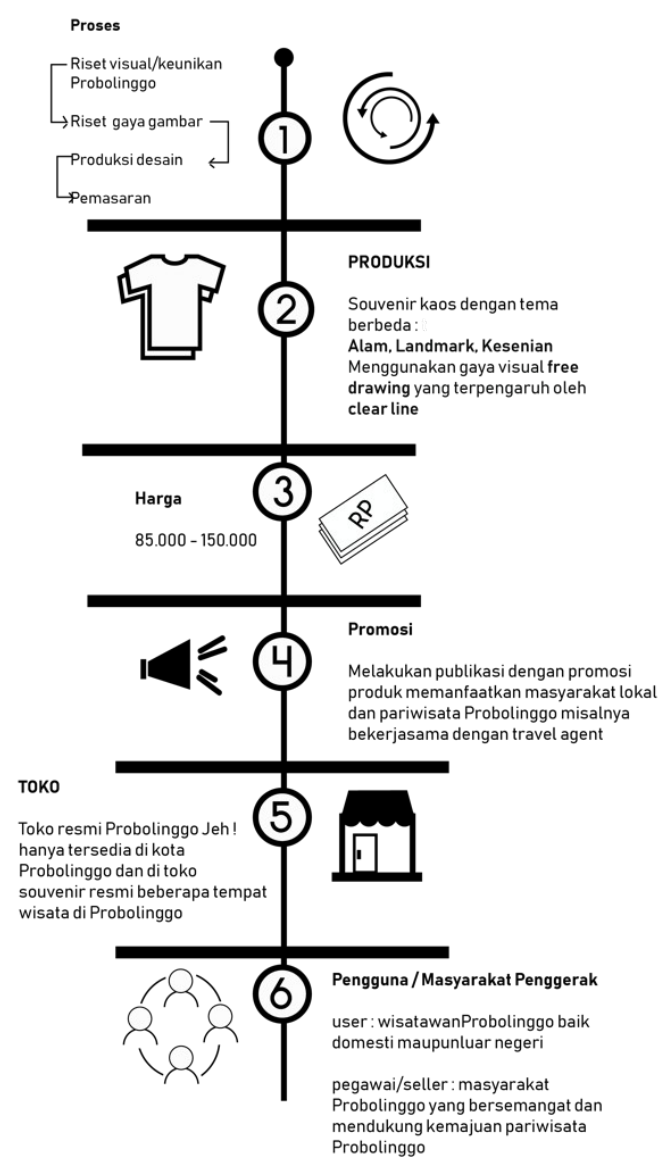

Gambar 8 Marketing Plan.

Dibutuhkan sistem bisnis dan produksi agar proses penjualan berjalan lancar.

Dari strategi marketing diatas terdapat Unique Selling Point ( USP ) sebagai berikut :

1. Mengangkat keunikan Probolinggo melalui gaya visual clear line

2. Memberi edukasi tentang Probolinggo dari objek \& budaya yang khas.

3. Bahan / material kaos menggunakan cotton combed 30 s atau bamboo cattoon yang sesuai untuk penggunaan kaos yang nyaman sebagai souvenir pariwisata.

4. Desain terbatas, tidak dijual dengan sistem partai.

5. Positioning sebagai pioneer kaos souvenir Probolinggo dengan konten daerah yang menunjukkan wisata alam meliputi Bromo, Madakaripura, Songa Adventure, dan Gili ketapang. Wisata Landmark BJBR dan Gereja Merah, serta 
Kesenian Budaya meliputi Jaran Bodhag, Karapan Kambing, Tari Glipang, dan Kasada.

\section{KESIMPULAN DAN SARAN}

\section{A. Kesimpulan}

1. Desain pada kaos sudah menunjukkan khas Probolinggo dengan illustrasi wisata alam serta kesenian yang saat ini sedang dikembangkan Probolinggo dan mulai dikenal oleh masyarakat, terutama Gunung Bromo yang Iconic. Beberapa konten menambah pengetahuan untuk target segmen tentang Probolinggo, karena selama ini hanya mengetahui Gunung Bromo.

2. Warna-warna yang digunakan sesuai karena mencerminkan ciri khas dari wisata alam Probolinggo serta warna kesenian dari Probolinggo yang cenderung cerah, kontras, dan festive.

3. Bahan pada pakaian yang sesuai untuk dijadikan sebagai produk souvenir kaos Probolinggo adalah Cotton Combed 30'S atau Bamboo cotton karena nyaman digunakan sehingga sesuai untuk berpergian di daerah tropis.

4. Teknik cetak yang baik untuk digunakan adalah sablon DTG (Direct To Garment) karena hasil sablon tajam dan merata di permukaan bahan kaos selain itu awet bila dicuci.

Harga kaos yang ditawarkan cocok dengan kualitas desain dan pasar.

\section{B. Saran}

1. Lebih mengolah layout dan memperbanyak varian dengan ilustrasi, karena melalui ilustrasi, pengguna dapat bercerita tentang tempat tersebut.

2. Ditambahkan desain yang lebih sederhana sebagai varian.

3. Model kaos diharapkan bervariasi. Seperti contoh untuk konten Bromo diaplikasikan pada kaos long sleeve karena di Bromo dingin, sedangkan untuk Gili Ketapang diaplikasikan pada tank top karena sesuai dengan cuacanya yang cenderung panas.

\section{DAFTAR PUSTAKA}

[1] Times Indonesia, "Times Indonesia," 2016. [Online]. Available: https://timesindonesia.co.id.

[2] B. Gordon, The Souvenir: Messenger of The Extraordinary. 1986.

[3] Littrell, Souvenir and Tourism Styles. 1994. 